\title{
3-VARIABLE DOUBLE $\rho$-FUNCTIONAL INEQUALITIES OF DRYGAS
}

\author{
Wenlong Sun, Yuanfeng Jin, Choonkil Park and Gang Lu
}

Abstract. Drygas introduced the functional equation $f(x+y)+f(x-y)=2 f(x)+f(y)+f(-y)$ in quasi-inner product spaces. In this paper, we introduce and solve 3 -variable double $\rho$ functional inequalities associated to the functional equation $f(x+y+z)+f(x+y-z)=2 f(x)+$ $2 f(y)+f(z)+f(-z)$. Moreover, we prove the Hyers-Ulam stability of the 3-variable double $\rho$-functional inequalities in complex Banach spaces.

Mathematics subject classification (2010): Primary 39B62, 39B52, 46B25.

Keywords and phrases: Drygas functional equation, Hyers-Ulam stability, double $\rho$-functional inequalities, Banach space.

\section{REFERENCES}

[1] T. AOKI, On the stability of the linear transformation in Banach spaces, J. Math. Soc. Japan 2 (1950), 64-66.

[2] J. Aczel And J. Dhombres, Functional Equations in Several Variables, Cambridge Univ. Press, Cambridge, 1989.

[3] P. W. CHOLEWA, Remarks on the stability of functional equations, Aequationes Math. 27 (1984), 76-86.

[4] Y. Cho, C. PARK AND R. SAADATI, Functional inequalities in non-Archimedean Banach spaces, Appl. Math. Lett. 23 (2010), 1238-1242.

[5] Y. Cho, R. SAADATI AND Y. YANG, Approximation of homomorphisms and derivations on Lie $C^{*}$ algebras via fixed point method, J. Inequal. Appl. 3013, 2013:415.

[6] H. DRYGAS, Quasi-inner products and their applications, Advances in Multivariate Statistical Analyis, 13-30, Theory Decis. Lib Ser. B: Math. Statist. Methods, Reidel, Dordrecht, 1987.

[7] A. Ebadian, N. Ghobadipour, Th. M. Rassias And M. Eshaghi GordJi, Functional inequalities associated with Cauchy additive functional equation in non-Archimedean spaces, Discrete Dyn. Nat. Soc. 2011 (2011), Article ID 929824.

[8] B. R. Ebanks, P. L. Kannappan And P. K. Sahoo, A common generalization of functional equations charactering normed and quasi-inner-product spaces, Canad. Math. Bull. 35 (1992), 321-327.

[9] W. FECHNER, Stability of a functional inequalities associated with the Jordan-von Neumann functional equation, Aequationes Math. 71 (2006), 149-161.

[10] P. GǍVRUTA, A generalization of the Hyers-Ulam-Rassias stability of approximately additive mappings, J. Math. Anal. Appl.184 (1994), 431-436.

[11] A. GilánYI, Eine zur Parallelogrammgleichung äquivalente Ungleichung, Aequationes Math. 62 (2001), 303-309.

[12] A. GilÁNYi, On a problem by K. Nikodem, Math. Inequal. Appl. 5 (2002), 707-710.

[13] D.H. HYERS, On the stability of the linear functional equation, Proc. Natl. Acad. Sci. USA 27 (1941), 222-224.

[14] G. LU, Q. LiU, Y. Jin And J. XIE, 3-Variable Jensen $\rho$-functional equations, J. Nonlinear Sci. Appl. 9 (2016), 5995-6003.

[15] G. LU AND C. PARK, Hyers-Ulam stability of additive set-valued functional equations, Appl. Math. Lett. 24 (2011), 1312-1316.

[16] G. LU AND C. PARK, Hyers-Ulam stability of general Jensen-type mappings in Banach algebras, Results Math. 66 (2014), 385-404.

[17] C. PARK, Additive $\rho$-functional inequalities and equations, J. Math. Inequal. 9 (2015), 17-26. 
[18] C. PARK, Additive $\rho$-functional inequalities in non-Archimedean normed spaces, J. Math. Inequal. 9 (2015), 397-407.

[19] C. PARK, Y. CHO AND M. HAN, Functional inequalities associated with Jordan-von-Neumann-type additive functional equations, J. Inequal. Appl. 2007 (2007), Article ID 41820.

[20] TH.M. RASSiAs, On the stability of the linear mapping in Banach spaces, Proc. Amer. Math. Soc. 72 (1978), 297-300.

[21] J. RÄTZ, On inequalities associated with the Jordan-von Neumann functional equation, Aequationes Math. 66 (2003), 191-200.

[22] S.M. Ulam, Problems in Modern Mathematics, Chapter VI, Science ed., Wiley, New York, 1940.

[23] T. Z. XU, J. M. RASSIAS AND W. X. XU, A fixed point approach to the stability of a general mixed additive-cubic functional equation in quasi fuzzy normed spaces, Internat. J. Phys. Sci. 6 (2011), 313324. 